\title{
ĐĀC ĐIỂM BƯớU GIÁP CƯỜNG GIÁP TRẺ EM
}

Hoàng Thị Thủy Yên, Nguyễn Thị Kim Oanh,

Bộ môn Nhi, Đại học Y Dược Huế

DOI: $10.47122 / v j d e .2020 .42 .13$

\section{ABSTRACT \\ Characteristics of goitre with \\ hyperthyrodism in children}

Hyperthyroidism is more common in children. Graves' disease is the most common cause for hyperthyroidism in children. Objective: The aim of this study was to describe the characteristics or goitre with hyperthyrodism in children. Methods: Cross-sectional descriptive study. This study included 41 patients from April 2019 to July 2020 at the Pediatric Service at Hue University of Medicine and Pharmacy Hospital. Results: Graves' disease is the most common cause for $67,4 \%$. There are $81.4 \%$ of patients use the wrong iodine salt. Type II goiter is the most common with $51.1 \%$. Exophthalmos was found only in the Graves' disease at $48.3 \%$. Common clinical symptoms are tremor $(46.5 \%)$, tachycardia $(44.1 \%)$. Thyroid ultrasound with angiogenesis is common in the Graves' disease. In the Graves' disease TSH concentration was lower, FT4 concentration was higher than that of hyperthyroid goitre group $\mathrm{p}<0.05$. Conclusions and recommendations: Use iodine salt properly for the community. Families with a history of Basedow's disease do not use iodized salt. Anti-TPO antibody test for all patients with goitre hyperthyroidism.

Key words: goitre, hyperthyrodism

\section{TÓM TÁT}

Bướu giáp cường giáp ngày càng hay gặp ở trẻ em. Bệnh Basedow là nguy ên nh ân hay gặp nhất. Bướu giáp cường giáp có liên quan đến sử dụng muối Iod ngày càng được ghi nhận. Đề tài tìm hiêu các đặc điểm và nguyên nhân bướu giáp cường giáp ở trẻ em. Phuơng pháp nghiên cúvu: Mô tả cắt ngang. Nghiên cứu có 41 bệnh nhi được tiến hành từ tháng 4/2019 đến tháng 7/2020 tại khoa Nhi tổng hợp Bệnh viện Trường Đại học Y Dược Huế. Kết quả: Nguyên nhân của bướu giáp cường giáp Basedow chiếm tỷ lệ 67,4\% Bướu giáp cường giáp 32,6\%. Có $81,4 \%$ bệnh nhân sử dụng sai muối Iode. Bướu giáp lớn độ II hay gặp nhất $51,1 \%$. Lồi mắt chỉ gặp ở nhóm Basedow với tỷ lệ 48,3\%. Các triệu chứng lâm sàng hay gặp là run tay $(46,5 \%)$, mạch nhanh $(44,1 \%)$. Siêu âm tuyến giáp có tăng sinh mạch hay gặp ở nhóm Basedow. Nồng độ TSH nhóm Basedow thấp hơn, nồng độ FT4 cao hơn nhóm bướu cường giáp $\mathrm{p}<0,05$. Kết luận và kiến nghị: Sử dụng muối iod đúng cách cho cộng đồng. Những gia đình có tiền sử bệnh Basedow th ì không sử dụng muối iod. Xát nghiệm kháng thể Anti-TPO cho tất cả bệnh nhân bướu giáp cường gi áp.

Tù kh óa: Bướu giáp, cường giáp

Chịu trách nhiệm chính: Hoàng Thị Thủy Y ên

Ngày nhận bài: 05/8/2020

Ngày phản biện khoa học: 06/9/2020

Ngày duyệt bài: 07/11/2020

Email: thuyyenhoangthi@yahoo.com

Điện thoại:0914126998

\section{1. ĐẠT VẤN ĐỀ}

Hiện nay, bướu giáp cường giáp có $x u$ hướng ngày càng tăng ở trẻ em. Bệnh cường giáp xảy ra ở khoảng 1 trên 5000 trẻ em và Basedow chiếm phần lớn trong số các trường hợp này [6], [7], [8], [9]. Bệnh bướu giáp cường giáp nếu không được chẩn đoán và điều trị sớm, có thể ảnh hưởng đến quá trình tăng trưởng và dậy thì, trẻ sẽ có chiều cao cuối thấp, ảnh hưởng tâm lý, sức khoẻ, học tập của trẻ [3], [4], [5]. Bệnh diễn tiến lâu dài, điều trị nhiều năm, hay tái phát nên ảnh hưởng chất lượng cuộc sống một cách đáng kể. Để góp phần chẩn đoán sớm và điều trị thích hợp, đề tài này được thực hiện nhằm tìm hiểu các đặc điểm bệnh lý và nguyên nhân của bướu giáp cường giáp trẻ em. 


\section{2. ĐỐI TƯợNG VÀ PHƯƠNG PHÁP NGHIÊN CỨU}

2.1. Đối tượng: Bệnh nhi chẩn đoán bướu giáp cường giáp được điều trị tại khoa Nhi tổng hợp - Bệnh viện Trường Đại học $\mathrm{Y}$ Dược Huế.

Tiêu chuẩn chọn bệnh

Bệnh nhi $\leq 15$ tuổi có dấu hiệu lâm sàng và cận lâm sàng sau:

L âm sàng: Bướu giáp lớn lan toả và có $\geq 1$ các dấu hiệu sau: thay đổi tính tình, nhịp tim nhanh, giảm cân, run tay, lồi mắt,...

Cận lâm sàng: Nồng độ TSH trong huyết thanh giảm $\mathrm{TSH} \leq 0,1 \mu \mathrm{IU} / \mathrm{ml}$.

Nồng độ FT4 trong huyết thanh tăng FT4 > $21 \mathrm{pmol} / 1$ [1].

Phân loại bướu giáp: Bướu giáp Basedow: bướu giáp lan tỏa cường giáp có Anti-TPOAb $(+)$ và Anti- TRAb (+) [10]. Bướu giáp cuờng gióp: bướu giáp lan tỏa nhưng kháng thể kh áng gi áp âm $t$ ńh : Anti-TPOAb (-) v à Anti - TgAb (-). Nghiên cứu có 29/43 (67,4\%) bệnh nhi Basedow và 14/43 (32,6\%) bệnh nhân bướu giáp cường giáp

Tiêu chuẩn loại trùt: Bướu giáp bình giáp , suy giáp , bướu giáp nhân...

Thời gian và địa điểm nghiên cứu: Nghiên cứu từ tháng $4 / 2019$ đến tháng 7/2020 tại khoa Nhi tổng hợp Bệnh viện Trường Đại học Y Dược Huế.

Thiết kế nghiên cứu: Mô tả cắt ngang.

Cõ̃ mẫu: Cỡ mẫu thuận tiện. Có 43 bệnh nhân đủ tiêu chuẩn chọn bệnh.

Xử lý số liệu: SPSS 18.0.

\section{KẾT QUẢ}

\section{1. Đặc điểm chung}

Bảng 3.1. Đặc điểm tuổi

\begin{tabular}{|l|c|c|c|c|c|}
\hline \multirow{2}{*}{ Tuối } & \multicolumn{2}{|c|}{$\begin{array}{c}\text { Basedow } \\
\mathbf{N}=\mathbf{2 9}\end{array}$} & \multicolumn{2}{c|}{$\begin{array}{c}\text { Bướu giáp cường gi áp } \\
\mathbf{N}=\mathbf{1 4}\end{array}$} & \multirow{2}{*}{$\mathbf{p}$} \\
\cline { 2 - 5 } & $\mathbf{n}$ & $\mathbf{\%}$ & $\mathbf{n}$ & $\mathbf{\%}$ & \\
\hline$<\mathbf{5}$ & 2 & 6,9 & 2 & 14,3 & \\
\cline { 2 - 5 } & 12 & 41,3 & 3 & 21,4 & \multirow{2}{*}{$\mathbf{0 , 0 5}$} \\
\hline$>\mathbf{1 0}$ & 15 & 51,8 & 9 & 64,3 & \\
\hline Tồng & $\mathbf{2 9}$ & $\mathbf{1 0 0}$ & $\mathbf{1 4}$ & $\mathbf{1 0 0}$ & \\
\hline
\end{tabular}

Bảng 3.2. Đặc điểm giới tính

\begin{tabular}{|c|c|c|c|c|c|}
\hline \multirow[t]{2}{*}{ Giới } & \multicolumn{2}{|c|}{$\begin{array}{c}\text { Basedow } \\
\mathbf{N}=\mathbf{2 9}\end{array}$} & \multicolumn{2}{|c|}{$\begin{array}{l}\text { Bướu giáp cường gi áp } \\
\qquad \mathrm{N}=14\end{array}$} & \multirow[t]{2}{*}{ p } \\
\hline & $\mathrm{n}$ & $\%$ & $\mathrm{n}$ & $\%$ & \\
\hline Nam & 6 & 20,7 & 3 & 21,4 & \multirow{3}{*}{$>0,05$} \\
\hline Nữ & 23 & 79,3 & 11 & 78,6 & \\
\hline Tổng & 29 & 100 & 14 & 100 & \\
\hline
\end{tabular}

Bảng 3.3. Phân bố địa dư

\begin{tabular}{|l|c|c|c|c|c|}
\hline \multirow{2}{*}{ Địa du } & \multicolumn{2}{|c|}{$\begin{array}{c}\text { Basedow } \\
\mathbf{n}=\mathbf{2 9}\end{array}$} & \multicolumn{2}{c|}{$\begin{array}{c}\text { Bướu giáp cường gi áp } \\
\mathbf{n = 1 4}\end{array}$} & \multirow{2}{*}{$\mathbf{p}$} \\
\cline { 2 - 5 } & $\mathbf{n}$ & $\mathbf{0}$ & $\mathbf{n}$ & $\mathbf{\%}$ & \\
\hline Th ành thị & 6 & 20,7 & 6 & 42,9 & \multirow{2}{*}{$>\mathbf{0 , 0 5}$} \\
\hline N ông th ôn & 23 & 79,3 & 8 & 57,1 & \\
\hline Tổng & $\mathbf{2 9}$ & $\mathbf{1 0 0}$ & $\mathbf{1 4}$ & $\mathbf{1 0 0}$ & \\
\hline
\end{tabular}


Bảng 3.4. Tiền sử gia đình

\begin{tabular}{|c|c|c|c|c|c|}
\hline \multirow{2}{*}{ Tiền sử gia đình } & \multicolumn{2}{|c|}{$\begin{array}{c}\text { Basedow } \\
\mathbf{N}=29\end{array}$} & \multicolumn{2}{|c|}{$\begin{array}{c}\text { Bướu giáp cường gi áp } \\
\mathrm{N}=14\end{array}$} & \multirow{2}{*}{$\mathbf{p}$} \\
\hline & $\mathbf{N}$ & $\%$ & $\mathbf{N}$ & $\%$ & \\
\hline Mắc bệnh Basedow & 11 & 37,9 & 0 & 0 & $<0.05$ \\
\hline Mắc bệnh bướu gi áp & 3 & 10,3 & 1 & 7,1 & \multirow{3}{*}{$>0,05$} \\
\hline Mắc bệnh tự miễn & 2 & 6,9 & 0 & 0 & \\
\hline Không mắc bệnh & 13 & 44,9 & 13 & 92,9 & \\
\hline Tổng & 29 & 100 & 14 & 100 & \\
\hline
\end{tabular}

Bảng 3.5. Tiền sử dùng muối iod

\begin{tabular}{|l|c|c|c|c|c|c|c|}
\hline \multirow{2}{*}{$\begin{array}{c}\text { Tiền sử } \\
\text { d ùng muối iod }\end{array}$} & \multicolumn{2}{|c|}{$\begin{array}{c}\text { Basedow } \\
\mathbf{N}=\mathbf{2 9}\end{array}$} & \multicolumn{2}{c|}{$\begin{array}{c}\text { BG cường gi áp } \\
\mathbf{N}=\mathbf{1 4}\end{array}$} & \multicolumn{2}{c|}{ Tổng } & \multirow{2}{*}{$\mathbf{4}$} \\
\cline { 2 - 7 } & $\mathbf{n}$ & $\mathbf{\%}$ & $\mathbf{n}$ & $\mathbf{\%}$ & $\mathbf{n}$ & $\mathbf{\%}$ & \\
\hline Sử dụng đúng & 7 & 24,1 & 1 & 7,1 & 8 & 18,6 & \multirow{2}{*}{$>0,05$} \\
\hline Sứ dụng sai & 22 & 75,9 & 13 & 92,9 & 35 & 81,4 & \\
\hline
\end{tabular}

Bảng 3.6. Triêu chứng lâm sàng

\begin{tabular}{|c|c|c|c|c|c|}
\hline \multirow{2}{*}{$\begin{array}{l}\text { Triệu chứng } \\
\text { lâm s àng }\end{array}$} & \multicolumn{2}{|c|}{$\begin{array}{c}\text { Basedow } \\
\mathbf{N}=29\end{array}$} & \multicolumn{2}{|c|}{$\begin{array}{l}\text { Bướu giáp cường gi áp } \\
\qquad \mathrm{N}=14\end{array}$} & \multirow{2}{*}{$\mathbf{p}$} \\
\hline & $\mathbf{n}$ & $\%$ & $\mathbf{n}$ & $\%$ & \\
\hline $\begin{array}{l}\text { Mạch nhanh } \\
n=19(44,1 \%)\end{array}$ & 17 & 58,6 & 2 & 14,3 & $<0,05$ \\
\hline Lồi mắt & 14 & 48,3 & 0 & 0,0 & $<0,05$ \\
\hline $\begin{array}{l}\text { Run tay } \\
\mathrm{n}=20(46,5 \%)\end{array}$ & 16 & 55,2 & 4 & 28,6 & $>0,05$ \\
\hline $\begin{array}{l}\text { Mệt mỏi } \\
\mathrm{n}=14(32,6 \%)\end{array}$ & 7 & 24,1 & 7 & 50,0 & $>0,05$ \\
\hline $\begin{array}{l}\text { Da n óng ẩm } \\
\mathrm{n}=17(39,5 \%)\end{array}$ & 12 & 41,4 & 5 & 35,7 & $>0,05$ \\
\hline $\begin{array}{l}\text { Gầy s út } \\
\mathrm{n}=18(41,9 \%)\end{array}$ & 14 & 48,3 & 4 & 28,6 & $>0,05$ \\
\hline $\begin{array}{l}\text { Hồi hộp } \\
\mathrm{n}=18(41,9 \%)\end{array}$ & 14 & 48,3 & 4 & 28,6 & $>0,05$ \\
\hline $\begin{array}{l}\text { Thay đổi } \mathbf{t} \text { ńh } \mathbf{t} \text { nh } \\
\mathrm{n}=12(27,9 \%)\end{array}$ & 9 & 31,0 & 3 & 21,4 & $>0,05$ \\
\hline $\begin{array}{l}\text { Mất ngủ } \\
\mathrm{n}=12(27,9 \%)\end{array}$ & 10 & 34,5 & 2 & 14,3 & $>0,05$ \\
\hline $\begin{array}{l}\text { Học kém } \\
\mathrm{n}=10(23,3 \%)\end{array}$ & 9 & 31,0 & 1 & 7,1 & $>0,05$ \\
\hline $\begin{array}{l}\text { Ăn nhiều } \\
n=10(23,3 \%)\end{array}$ & 9 & 31,0 & 1 & 7,1 & $>0,05$ \\
\hline $\begin{array}{l}\text { Ti êu chảy } \\
\mathrm{n}=9(20,9 \%)\end{array}$ & 6 & 20,7 & 3 & 21,4 & $>0,05$ \\
\hline $\begin{array}{l}\text { Huyết áp cao } \\
\mathrm{n}=7(16,3 \%)\end{array}$ & 6 & 20,7 & 1 & 7,1 & $>0,05$ \\
\hline Kh ác & 2 & 6,9 & 4 & 28,6 & $>0,05$ \\
\hline
\end{tabular}


Bảng 3.7. Đặc điểm bướu giáp

\begin{tabular}{|c|c|c|c|c|c|c|}
\hline \multirow{2}{*}{\multicolumn{2}{|c|}{ Đặc điểm }} & \multicolumn{2}{|c|}{$\begin{array}{c}\text { Basedow } \\
\mathrm{N}=29\end{array}$} & \multicolumn{2}{|c|}{$\begin{array}{l}\text { Bướu giáp cường gi áp } \\
\mathrm{N}=14\end{array}$} & \multirow[t]{2}{*}{$\mathbf{p}$} \\
\hline & & $\mathbf{n}$ & $\%$ & $\mathbf{n}$ & $\%$ & \\
\hline \multirow{3}{*}{$\begin{array}{l}\text { Phân độ } \\
\text { bướu gi áp }\end{array}$} & $\begin{array}{l}I \\
N=10 \\
(23,3 \%)\end{array}$ & 3 & 10,3 & 7 & 50 & \multirow{3}{*}{$<0,05$} \\
\hline & $\begin{array}{l}\text { II } \\
N=22 \\
(\mathbf{5 1 , 1 \%})\end{array}$ & 16 & 55,2 & 6 & 42,9 & \\
\hline & $\begin{array}{l}\text { III } \\
N=11 \\
(25,6 \%)\end{array}$ & 10 & 34,5 & 1 & 7,1 & \\
\hline \multirow{2}{*}{ Mật độ } & Mềm & 26 & 89,7 & 11 & 78,6 & \multirow{2}{*}{$>0,05$} \\
\hline & Chắc & 3 & 10,3 & 3 & 21,4 & \\
\hline \multirow{2}{*}{$\begin{array}{l}\text { Tiếng thổi } \\
\text { tại bướu }\end{array}$} & Có & 7 & 24,1 & 0 & 0 & \multirow[b]{2}{*}{$<0,05$} \\
\hline & Kh ông & 22 & 75,9 & 14 & 100 & \\
\hline
\end{tabular}

Bảng 3.8. Thể tích bướu giáp theo siêu âm

\begin{tabular}{|l|c|c|c|}
\hline Thể $\mathbf{t}$ ćh tuyến gi áp & $\begin{array}{c}\text { Basedow } \\
\mathbf{N}=\mathbf{2 9}\end{array}$ & $\begin{array}{c}\text { Bướu giáp cường gi áp } \\
\mathbf{N}=\mathbf{1 4}\end{array}$ & $\mathbf{p}$ \\
\hline $\mathbf{X} \pm \mathbf{S D}$ & $17,2 \pm 3,75$ & $12,4 \pm 6,05$ & $<0,05$ \\
\hline
\end{tabular}

Bảng 3.9. Đặc điểm bướu giáp theo siêu âm

\begin{tabular}{|c|c|c|c|c|c|c|}
\hline \multirow{2}{*}{\multicolumn{2}{|c|}{ Đặc điểm }} & \multicolumn{2}{|c|}{$\begin{array}{c}\text { Basedow } \\
(n=29)\end{array}$} & \multicolumn{2}{|c|}{$\begin{array}{l}\text { Bướu giáp cường } \\
\text { gi áp }(n=14)\end{array}$} & \multirow[b]{2}{*}{$\mathbf{p}$} \\
\hline & & $\mathrm{n}$ & $\%$ & $\mathrm{n}$ & $\%$ & \\
\hline \multirow{2}{*}{$\begin{array}{l}\text { Tăng sinh } \\
\text { mạch m áu }\end{array}$} & Tăng sinh mạch & 20 & 69,0 & 3 & 21,4 & \multirow{2}{*}{$<0,05$} \\
\hline & Không tăng sinh & 9 & 31,0 & 11 & 78,6 & \\
\hline \multirow{2}{*}{$\begin{array}{l}\text { Hạch } \\
\text { cố }\end{array}$} & Có & 2 & 6,9 & 4 & 28,6 & \multirow[b]{2}{*}{$>0,05$} \\
\hline & Kh ông & 27 & 93,1 & 10 & 71,4 & \\
\hline
\end{tabular}

Bảng 3.10. Nồng độ hormon trục giáp

\begin{tabular}{|c|c|c|c|}
\hline TSH (mUI/ml) & $\begin{array}{c}\text { Basedow } \\
\mathbf{N}=\mathbf{2 9}\end{array}$ & $\begin{array}{l}\text { Bướu giáp cường gi áp } \\
\qquad \mathrm{N}=14\end{array}$ & $\mathbf{p}$ \\
\hline Trung vi & 0,005 & 0,011 & \multirow{2}{*}{$<0,05$} \\
\hline $95 \% \mathrm{CI}$ & $0,005-0,006$ & $0,005-0,019$ & \\
\hline \multirow[t]{2}{*}{ FT4 $(\mathrm{pmol} / \mathrm{ml})$} & 87,1 & 25,7 & \multirow[b]{2}{*}{$<0,05$} \\
\hline & $46,6-100,3$ & $19,8-43,1$ & \\
\hline
\end{tabular}

\section{BÀN LUẬn}

\section{1. Đặc điểm chung}

Các bảng $3.1,3.2,3.3$ và 3.4 cho thấy nhóm nghiên cứu gồm 29 trường hợp Basedow và 14 trường hợp bướu giáp cường giáp nhận thấy không có sự khác biệt về tỷ lệ phân bố nhóm tuổi, giới tính, đặc điểm địa dư và tiền sử dụng iod giữa các nguy ên nh ân bệnh nguyên. Đa số bướu giáp cường giáp gặp nhiều ở đối tượng là nữ trong độ tuồi dậy thì, chủ yếu sống ở nông thôn và sử dụng lượng muối iod như món ăn phụ nhiều hơn 
[4] ,[5]. Các nghiên cứu nước ngoài cung nhận thấy dùng muối Iode cho cộng đồng gây rối loạn chức năng giáp gây nhiễm độc giáp [6], [7], [8], [9]. Bên cạnh đó nghiên cứu cũng cho thấy có sự khác biệt có ý nghĩa thống kê với $\mathrm{p}<0,05$ về tiền sử gia đình mắc bệnh lý Basedow giữa các nhóm nguyên nhân bướu giáp cường giáp. Tiền sử gia đìh Basedow sẽ là yếu tố thuận lợi gợi ý bệnh Basedow hơn là bướu giáp cường giáp [10].

\section{2. Đặc điểm lâm sàng}

\subsection{1. Đặc điểm bướu gi ớp}

Bảng 3.7 cho thấy nhóm Basedow, độ lớn bướu gi áp chủ yếu là độ II, III ( 90\%) ngược lại bướu giáp cường gi ấp khác th ì thể $t$ ć tuyến gi áp chủ yếu là độ $\mathrm{I}, \mathrm{II}(>90 \%)$. Điều này tương đương với nghi ên cứu của Nguyễn Thị Thảo Trinh về bệnh Basedow trẻ em, bướu giáp độ II, III chiếm tỉ lệ rất cao (>90\%) [5]. Bướu giáp cũng là triệu chứng dễ $\mathrm{d}$ àng nh h̀ thấy trên lâm sàng nên đó cũng là những triệu chứng đầu ti ên khiến bệnh nh ân $\mathrm{v}$ ào viện. $\mathrm{V}$ à sự kh ác biệt này có ý nghĩa thống $\mathrm{k}$ ê với $\mathrm{p}<0,05$. Ngo ài ra nghi ên cứu c òn cho thấy có sự khác biệt về đặc điểm tiếng thổi tại bướu với $p<0,05$. Ở bệnh nh ân Basedow chủ yếu bướu gi áp mềm, lan toả, $\mathrm{v}$ à c ó tiếng thổi, ngược lại bướu giáp cường gi áp th ì không. Trong nghi ên cứu của Nguyễn Thị Thảo Trinh c ó $90.9 \%$ bướu gi áp mềm, lan toả, v à $25 \%$ có tiếng thổi [5]. Sự xuất hiện tiếng thổi có giá trị trong chẩn đoán bướu gi áp basedow. Kết quả $n$ ày ph ù hợp c ác nghi ên cứu khác [6], [10].

4.2.2. Nhận $x$ ét về triệu chúng lâm sàng.

Sự kh ác biệt về triệu chứng 1 âm $\mathrm{s}$ àng giữa 2 nhớm nghi ôn cứu là lồi mắt với $\mathrm{p}<0,05$ ( Bảng 3.6), lồi mắt là một trong những triệu chứng đặc thù của Basedow. Tỉ lệ bệnh nh ân c ó lồi mắt trong nghi ôn cứu $n$ ày 1 à $48,3 \%$, thấp hơn so với nghi ên cứu của Nguyễn Thị Thảo Trinh $72,72 \%$. Vì đối tượng nghi ên cứu của nghi ên cứu trên là bệnh nh ân Basedow n ên gặp với tỉ lệ cao hơn.

Lồi mắt $\mathrm{c}$ ó bản chất là tăng sinh, phù nề, th âm nhiễm ở tổ chức sau nh ãn cầu và tăng lực đẩy nhãn cầu ra phía trước. V à đặc điểm lồi mắt sẽ không bị mất đi mặc dù được điều trị và trở về b h̀h gi áp. Tuy nhi ên hầu hết $\mathrm{c}$ ác nghi ên cứu cho rằng lồi mắt trong Basedow trẻ em là nhẹ và $\mathrm{t} g$ ây ra $\mathrm{c}$ ác biến chứng hơn so với người lớn [3], [10]. Ngo ài ra mạch nhanh cũng là triệu chứng gợi ý để ph ân biệt các nguyên nhân bướu giáp cường gi ấp, trong nghi ên cứu này tỷ lệ bệnh Basedow có triệu chứng mạch nhanh chiếm ưu thế. Sự khác biệt này có ý nghĩa thống $\mathrm{k}$ êvới $\mathrm{p}<0,05$.

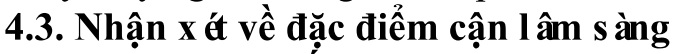 4.3.1. Si êu âm tuyến giớp}

Si âu âm cho thấy có sự khác biệt về thể $\mathrm{t}$ ch trung $\mathrm{b}$ h̀h tuyến gi áp giữa 2 nhóm đối tượng nghi ân cứu với $\mathrm{p}<0,05$. Bệnh nhân Basedow có thể $t$ ćch tuyến gi áp trung $b$ ǹh lớn hơn, tương ứng với độ lớn bướu gi áp tr ên 1 âm $\mathrm{s}$ àng. Ngo ài sự tăng về thể $\mathrm{t}$ chh, $h$ ǹh ảnh điển $\mathrm{h}$ ǹh của Basedow 1 à sự tăng sinh mạch máu. Trong nghiên cứu này $96 \%$ bệnh nhân basedow có tăng sinh mạch tr ên si êu âm.

\subsubsection{Nồng độ hormon trục tuyến y ên- tuyến gi ớp}

Nồng độ FT4 tăng và FSH gợi ý một $\mathrm{t}$ h̀h trạng cường gi áp. Tuy nhi ên ở bệnh nh ân Basedow, nồng độ TSH thấp hơn rất nhiều, $\mathrm{v}$ à FT4 cao hơn nhiều so với các nguy ên nh ân còn lại. Điều đó được thể hiện qua gi á trị trung vị của TSH và FT4. Sự khác biệt c ó ý nghĩa với $\mathrm{p}<0,05$.

\section{KẾT LUÂN}

\section{Đặc điểm lầm s àng:}

Bướu giáp cường gặp ở nữ chiếm 76,7 \%

Nhóm tuổi chiếm tỷ lệ cao nhất $>10$ tuổi $55,8 \%$, nh óm tuổi < 5 tuổi rất hiếm gặp, có 4 case chiếm $9,3 \%$. Tiền sử gia đình mắc bệnh lýtuyến gi áp chiếm 34,9\%, trong đó Basedow có 11 trường hợp chiếm $25,6 \% .81,4 \%$ trường hợp sử dụng sai muối iod, và sai thừa chiếm chủ yếu. Bướu gi áp lớn lan toả, độ II chiếm đa số với $51,2 \%$. Đặc điểm 1 âm $s$ àng chỉ gặp ở nhóm Basedow làlồi mắt c ótỷ lệ 48,3\%, mạch nhanh tỷ lệ 24,1\%., bướu gi áp lớn hơn ở nhóm Basedow và bướu giáp cường gi áp khác, sự khác biệt có ý nghĩa thống k ê với $\mathrm{p}<0,05$. Có sự khác biệt về tiền sử gia đình mắc bệnh $1 y ́$ tuyến giáp, đặc biệt tiền sử bị Basedow cao ở nh óm Basedow với $\mathrm{p}<0,05$. 
Cận lâm s àng: Cósự kh ác biết về thể t ch tuyến giáp, đặc điểm nhu mô tuyến giáp, đặc điểm tăng sinh mạch trên si âl âm giữa các nhóm bướu gi áp theo phân loại bướu gi áp cường gi áp, sự kh ác biệt có ý nghĩa thống $\mathrm{k} \hat{\mathrm{e}}$ với $\mathrm{p}<0,05$.

\section{KIẾN NGH!}

Sử dụng muối iod đúng cách cho cộng đồng. Những gia đình có tiền sử bệnh Basedow th ì kh ông sử dụng muối iod . Xát nghiệm kh áng thể Anti-TPO cho tất cả bệnh nhân bướu giáp cường gi ấp.

\section{TÀI LIỆ THAM KHẢO}

1. Bộ Y Tế (2015), Cường chưc năng tuyến gi óp, Hướng dẫn chẩn đoán bệnh nội tiết chuyển hoá, Nhà xuất bản Y học

2. Hoàng Kim Ước (2005), Nghiên cứu tình hình mắc cưòng giáp trạng sau bổ sung I-ốt và các yếu tố liên quan, Đại học Y Hà Nội, Hà Nội.

3. Hoàng Thị Thuỷ Yên (2009), Cường giáp trẻ em, Giáo trình sau đại học tập 4 , Nhà xuất bản Đại học Huế, TP. Huế.

4. Nguyễn Thị Thanh Xuân (2006), Nghiên cưu một số đặc điểm lâm sàng và xét nghiệm cận lâm sàng của buớu giáp cuờng giáp ở trẻ em, Trường Đại học $\mathrm{Y}$ Dược Huế.

5. Nguyễn Thị Thảo Trinh (2011), Nghi ên cưu đặc điểm lâm sàng, cận lâm sàng bệnh Basedow trẻ em tại khoa Nhi Bệnh viện Trung Uơng Huế, Trường Đại học $\mathrm{Y}$ dược Huế.

6. Ada Borowiec et al (2018), Grave's disease in children in the two decades following implementation of an iodine

7. Hunt P. J Brownlie B.E, Turner J. G, (2010), Thyrotoxicosis a South Island, New Zealand experience with long term outcome, The New Zealand Medical Journal.

8. M. Leung and L. E. Braverman (2012), "Iodine-induced thyroid dysfunction", Curr Opin Endocrinol Diabetes Obes. 19(5), tr. 414-9.

9. MD. Martin I Surks (2019), "Iodineinduced thyroid dysfunction".

10. MD Stephen LaFranchi (2019), Clinical manifestations and diagnosis of Graves disease in children and adolescents, Oregon Health \& Sciences University. 